\title{
Causes of anger among senior high school students in Indonesia: An indigenous psychology approach
}

Thontowi, Haidar Buldan

Center for Indigenous \& Cultural Psychology, Faculty of Psychology, Universitas Gadjah Mada, Yogyakarta, Indonesia (haidar.buldan@gmail.com)

Wulandari, Rr. Cahya

Center for Indigenous \& Cultural Psychology, Faculty of Psychology, Universitas Gadjah Mada, Yogyakarta, Indonesia (wulandaricahya@gmail.com)

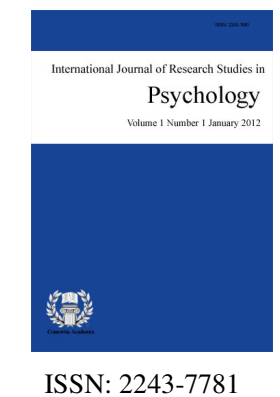

Hakim, Mohammad Abdul

Center for Indigenous \& Cultural Psychology, Faculty of Psychology, Universitas Gadjah Mada, Yogyakarta, Indonesia (hakimpsi@yahoo.com)

Moordiningsih

Center for Indigenous \& Cultural Psychology, Faculty of Psychology, Universitas Gadjah Mada, Yogyakarta, Indonesia (moordiningsih@yahoo.com)

Yuniarti, Kwartarini Wahyu $\unrhd$

Center for Indigenous \& Cultural Psychology, Faculty of Psychology, Universitas Gadjah Mada, Yogyakarta, Indonesia (kwartarini_yuniarti@yahoo.com)

Kim, Uichol

College of Business Administration, Inha University, Incheon, Korea (uicholk@yahoo.com)

Received: 15 March $2013 \quad$ Revised: 3 October $2013 \quad$ Accepted: 3 November 2013 Available Online: 9 February $2014 \quad$ DOI: $10.5861 /$ ijrsp.2014.104

OPEN ACCESS

\section{Abstract}

Appraisal theorists have argued that anger is elicited when important goals have been obstructed. Using an indigenous psychology approach, the current study aims to test this premise by investigating the events that account for a person's anger among Indonesian senior high school students. Data was collected using the anger item from the Happiness open-ended questionnaire, asking about events that make the subjects' most angry. A total of 425 senior high school students consisting of 171 males and 254 females were involved in the study. The data was analyzed using an indigenous psychological approach by analyzing the content of the open-ended responses, categorization of the responses, and cross-tabulations with the respondent's sex. The findings suggest that Indonesian senior high school students become angry when they their trust has been violated, insulted, encounter an unpleasant experience, and disturbance. Further analysis was conducted to identify variability upon male and female subjects. The chi square test that was run towards the variables events for causing anger and sex indicated a significant relationship $(p<0.03)$. Male respondents were most likely to become angry when encountering unpleasant experiences while females were most likely to become angry when their trust has been violated. The findings are contrary to the notions that goal obstruction is central in eliciting anger.

Keywords: anger; appraisal; sex; indigenous; adolescents 


\section{Causes of anger among senior high school students in Indonesia: An indigenous psychology approach}

\section{Introduction}

Anger is no doubt an interesting and important issue to study. If each person earned the ability to manage their anger effectively as to avoid destructive behaviors and harm other people, than the urgency to study anger would be somewhat undermined. The fact is that the individuals who dwell this earth possess a variety of characteristics who cannot guarantee the ability to manage anger in a positive manner. As a highly social emotion (Schieman, 2010) its implications are social and when they are destructive, society will bear its consequences. In order to understand the nuts and bolts of anger, further inquiry is required to understand what causes anger itself. As it is with most problems, solutions are derived from the identification of its causes.

Explaining the causes of anger is certainly not a simple matter considering the complexity of its nature. Several approaches have been used to resolve this issue and the following explanations will consider some of the contributions made by theorists. Averill (1983) addressed numerous aspects of anger using a survey method. With regard to the causes of anger, Averill made a distinction between the perceived causes of anger made by psychologists which were derived from the psychology literature and perceived causes of anger made by laypersons. The study revealed that frustration — interruption of a planned activity — is an important cause for anger together with other causes for example the loss of pride or self esteem, the violation of personal wishes and accepted social norms. Other researchers used an experimental approach to examine the causes of anger. Smith and Ellsworth (1985) asked subjects to recall on emotionally arousing events and then report their appraisals and emotions to the researchers. Concerning anger in particular, participants were angry when other people were responsible for the unpleasant or aversive experience. This finding was confirmed in a later study by Ellsworth and Smith (1988) who took a similar approach by asking subjects to recall on emotionally arousing experiences; however this study only required recalling unpleasant experiences. In addition to the factor of blaming another person as a cause of anger, goal obstruction was argued as an appraisal central to anger. Anger was also explained to motivate a person to remove the obstacle which becomes the source of the unpleasant experience.

Later studies attempting to explain the causes of anger used a taxonomy or categorization of subject responses (Carpenter \& Halberstadt, 1996; Weber, 2004). Carpenter and Halberstadt (1996) present a unique approach in studying anger. Firstly, the study explains the causes of anger under the context of family relationships. Second, similar to Averill's study (1983), the authors drew a distinction between the causes of anger from a psychologists' perspective and a laypersons' perspective. The results indicate that parents' anger at each other are caused by money issues, children issues, personality deficiencies, and inadequate time. Furthermore, parents' anger at children was caused by disobedience/ not listening, naughty behaviors, and personality deficiencies. Finally children's anger at parents was caused by inadequate attention, discipline, unfair treatment, and not getting one's way.

With regard to the distinctions between laypersons and psychologists in identifying the causes of anger, layperson's classification of anger causes were more focused on specific topics while the psychologists' categorization focused on underlying emotional experience for example violation of personal or social contract or loss of power, status or respect. The study also explained that the differences in categorization were due to the differences of level of abstraction between laypersons and psychologists, with psychologists being more able to convey abstract ideas. Furthermore, Weber's study (2003) investigated the causes of anger by interviewing 400 subjects with varying educational levels. The subjects' responses were subsequently coded into categories that were derived from existing theoretical and empirical literature. The findings revealed that from the total number of subjects $27 \%$ reported frustration or goals that were not achieved, $21 \%$ reported insults, $16 \%$ reported their 
own upsetting or annoying habits, $15 \%$ reported violation of social or personal standards, and $14 \%$ reported someone else's upsetting or annoying habits.

In addition to the studies that have been presented above, some attempts have been made by theorists to summarize the empirical literature pertaining to the causes of anger (Kuppens, Mechlehen, Smits, \& Boek, 2003; Berkowitz, 2003). Kuppens et al. (2003) suggested several components that were relevant to anger, namely the appraisals of goal obstacle (something or someone blocks the execution of activities or goals), other accountability (other people are responsible or are to blame), unfairness, control (the ability of a person to control the situation). Berkwoitz's article (2003) which stimulated enthusiast debates among theorists suggests that goal obstruction by external factors, blame, unfairness and illegitimacy and coping potential sparked anger. Coping potential in this context refers to the person's perceived ability to deal with the eliciting event.

Although providing useful explanations to understand the causes of anger, the literature above is vulnerable to external validity, since they were all conducted in developed countries and individualistic cultures. Studies on the causes of anger in different cultural contexts are required to either confirm or falsify the already existing theories to provide the academic community with a comprehensive understanding of the causes of anger. Matsumoto, Yoo, and Chung (2010) suggest that different expression patterns of anger are evident between collectivistic cultures and individualistic cultures. He suggests that culture calibrate the expressive and behavioral components of emotion via social roles and norms known as display rules. Mesquita (2003) further suggests that cultural differences have been identified in the initial response tendencies of appraisal, action readiness, expression and instrumental behavior, as well as regulations strategies.

An important study addressing this issue was conducted by Roseman, Dhawan, Rettek, Naidu, and Thapa (1995). This study compared the appraisals and emotional reactions of Americans and Indians. It was discovered that with regard to appraisal, Indians perceived greater causation by circumstances than did Americans in anger elicitation situations. However no significant cultural differences in perceived circumstance-causation were found for sadness or fear. The results also demonstrate robust differences between Americans and Indians in appraisals of situational state, power, and probability where Indians appraised sadness, fear, and anger-causing incidents as more consistent with their motives; appraised their power in the situation as lower; and appraised probability as lower (uncertainty).

In addition to contrasting differences, a number of similarities were also found. Both American and Indians appraisals of powerlessness characterized incidents eliciting anger and fear, whereas appraisals of relative power characterized incidents eliciting anger. In addition both Americans and Indians the appraisal that an event was caused by another person characterized incidents eliciting anger rather than sadness or fear. For American and Indians it was also found that the appraisal that an event was caused by circumstances characterized eliciting sadness and fear more so than anger although this difference only reached significance for the American sample. Finally, for both Indians and Americans, certainty was as low in incidents eliciting sadness as in incidents eliciting fear.

Taking these elaborations into consideration the current study aims to enrich the current literature on the causes of anger using an indigenous psychology approach. Indigenous psychology advocates examining the knowledge, skills, and beliefs people have about themselves and how they function in their familial, social, cultural, and ecological context and emphasizes obtaining a descriptive understanding of human functioning in a cultural context (Kim, Yang, \& Hwang, 2006). Furthermore indigenous psychology aims to create a more rigorous, systematic, and universal science that can be theoretically and empirically verified (Kim, Yang, and Hwang, 2006). The study will be performed in Indonesia, a collectivistic culture, and will investigate this phenomenon on adolescents.

Adolescents are particularly important to investigate considering that anger experiences are more prevalent among younger ages (Scheiman, 1999). The adolescent phase itself is marked by a phase of difficulty which Arnett (1999) suggested to be composed of three elements namely: Conflict with parents, implying that 
adolescents tend to be rebellious and resist adult authority; mood disruptions, in that adolescents tend to be more volatile emotionally either than children or adults; and risk behavior, implying that adolescents have higher rates of reckless, norm breaking, and antisocial behavior than either adults of children. Accordingly, the researcher views that these elements are significant with the investigation of anger.

Another aspect that will be considered in this study is the factor of sex and whether variations of sex will also appear related to the appraisals of anger causes. According to Fischer and Evers (2010) men and women are similar in anger experience with regard to intensity and frequency; however they suggest that differences may appear with regard to the causes of their anger. Furthermore the authors explain that women are less likely than men to directly express their anger since they are more concerned about the negative effects of their anger, particularly if the anger may harm social relationships.

\section{Method}

\subsection{Participants}

The participants in this study include a total of 425 senior high schools students from Yogyakarta consisting of 171 male and 254 female students aged between 14-18 years.

\subsection{Measures}

Data was collected using an open-ended questionnaire asking about what events makes the subjects most angry. The subjects were asked to write down their responses in the provided space and the subjects' responses were later categorized. Categorization was performed using open coding, axial coding and selective coding (Strauss, 2003). Open coding refers to the process of scrutinizing the field notes, interview or other document very closely, line by line or word by word, to produce concepts that seem to fit the data. Axial coding refers to the process of intense analysis done around one category at a time, in terms of the paradigm items (conditions, consequence, and many others). Axial coding is said to produce cumulative knowledge about relationships between that category and other categories and subcategories. Finally, selective coding refers to systematically coding for the core category or in other words, delimiting coding to only those codes that relate to core codes.

The categorization of the themes was conducted by researchers 3 researchers from the center of indigenous and cultural psychology supervised by an associate professor from the Faculty of Psychology, Universitas Gadjah Mada, Indonesia. The categorized responses were then cross-tabulated with the background information of sex.

\section{Results}

The figure below indicates the events that make the subjects most angry. It is evident from the results that having their trust violated is what makes most senior high school students angry. The thematic analysis performed resulted in four major categories namely violation of trust (23.8\%), insults (22.6\%), unpleasant experiences $(22.1 \%)$, and disturbance $(19.8 \%)$. The first category is violation of trust. This category consists of deception (48.5\%), betrayal (44.6\%), violation of commitment (3\%), and broken promise (4\%).

"When the people that we love or are close to lie to us"

"When someone breaks his/her promise"

"When my friend or girl/boyfriend betrays me"

The second category insults consist of being insults (27.1\%), slander (24\%), underestimation (14.6\%), not appreciated (12.5\%), false accusations (11.5\%) ignored (8.3\%), insult on religion (1\%), subject to harsh 
treatment (1\%). Typical responses for the category insults include:

"I was excessively insulted by someone"

"Someone insulted my parents"

"My self esteem and hard work was not appreciated at all"

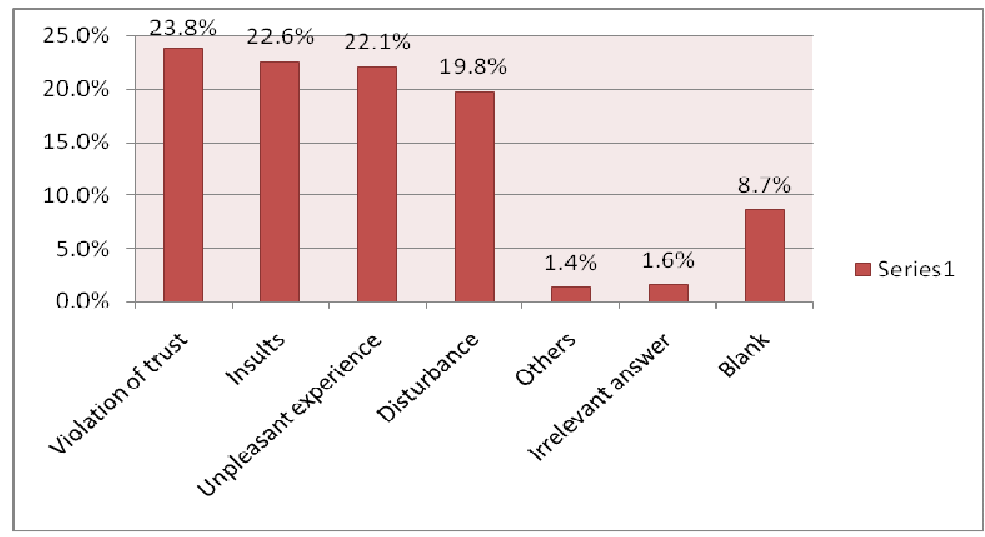

Figure 1. Causes of anger among senior high school students

The third category contributing to a person's anger is unpleasant experience. This category consists of the following; failure $(20.2 \%)$ subject to someone's anger (10.6\%) disappointment at someone (9.6\%) problems in intimate relationship $(9.6 \%)$ waiting $(8.5 \%)$ loss of a loved one/family member $(6.4 \%)$ family conflict $(6.4 \%)$ witness friend/close friend be harmed (6.4\%) not understood $(4.3 \%)$, loss of property/belonging (3.2\%) wrongdoing $(2.1 \%)$ dispute with another person $(2.1 \%)$ witness other people being harmed $(1.1 \%)$ parents argue (1.1\%) personal conflict with another person (1.1\%) disappointment to other $(1.1 \%)$ and physical pain $(1.1 \%)$. Some typical responses include:

\section{"Failed to make my parents happy" \\ "Someone got mad at me without any clear reason" \\ "Broke up with my girlfriend”}

The last category of disturbance consisted of annoying behavior of others (42.9\%), unfair treatment (14.3\%) mockery $(9.5 \%)$, disturbance $(8.3 \%)$, limitation of freedom $(7.1 \%)$, belongings were taken/broken by others $(4.8 \%)$, disrespect towards privacy (4.8\%), increased burden by others (3.6\%), forced (2.4\%), back biting (2.4\%). Typical responses for this category include:

\section{"When there is someone that always disturbs my life" \\ "When someone intervened too much into my problems" \\ "When my privacy is disturbed by other people"}

Cross tabulation was subsequently conducted towards the categories against the sex of the subjects. The analysis revealed that different patterns of the causes of anger were apparent among male and female Indonesian students (Pearson Chi-square 13.67; $p<.05$ ). Male students reported most anger when experiencing an unpleasant experience $(26 \% .9)$. On the other hand female students reported anger when their trust has been violated $(28 \%)$. 


\section{Table 1}

Categorization of subjects' causes of anger

\begin{tabular}{|c|c|c|c|}
\hline Items & Total & Male & Female \\
\hline Violation of trust & $101(23.8 \%)$ & $30(17.5 \%)$ & $71(28.0 \%)$ \\
\hline Deception & $49(48.5 \%)$ & $13(43.3 \%)$ & $36(34.4 \%)$ \\
\hline Betrayal & $45(44.6 \%)$ & $15(50.0 \%)$ & $30(42.3 \%)$ \\
\hline Violation of commitment & $3(3.0 \%)$ & $2(6.7 \%)$ & $1(1.4 \%)$ \\
\hline Broken promise & $4(4.0 \%)$ & $0(0 \%)$ & $4(5.6 \%)$ \\
\hline Insults & $96(22.6 \%)$ & $36(21.1 \%)$ & $60(23.6 \%)$ \\
\hline Insults & $26(27.1 \%)$ & $13(36.1 \%)$ & $13(21.7 \%)$ \\
\hline Slander & $23(24.0 \%)$ & $10(27.8 \%)$ & $13(21.7 \%)$ \\
\hline Underestimation & $14(14.6 \%)$ & $5(13.9 \%)$ & $9(15.0 \%)$ \\
\hline Not appreciated & $12(12.5 \%)$ & $5(13.9 \%)$ & $7(11.7 \%)$ \\
\hline False accusations & $11(11.5 \%)$ & $1(2.8 \%)$ & $10(16.7 \%)$ \\
\hline Ignored & $8(8.3 \%)$ & $2(5.6 \%)$ & $6(10.0 \%)$ \\
\hline Insult on religion & $1(1.0 \%)$ & $0(0 \%)$ & $1(1.0 \%)$ \\
\hline Subject to harsh treatment & $1(1.0 \%)$ & $0(0 \%)$ & $1(1.0 \%)$ \\
\hline Unpleasant experience & $94(22.1 \%)$ & $46(26.9 \%)$ & $48(18.9 \%)$ \\
\hline Failure & $19(20.2 \%)$ & $12(26.1 \%)$ & $7(14.6 \%)$ \\
\hline Subject to someone's anger & $10(10.6 \%)$ & $7(15.2 \%)$ & $3(6.3 \%)$ \\
\hline Disappointment at someone & $9(9.6 \%)$ & $5(10.9 \%)$ & $4(8.3 \%)$ \\
\hline Problems in intimate relationship & $9(9.6 \%)$ & $4(8.7 \%)$ & $5(10.4 \%)$ \\
\hline Waiting & $8(8.5 \%)$ & $2(4.3 \%)$ & $6(12.5 \%)$ \\
\hline Loss of loved one/family member & $6(6.4 \%)$ & $3(6.5 \%)$ & $3(6.3 \%)$ \\
\hline Family conflict & $6(6.4 \%)$ & $2(4.3 \%)$ & $4(8.3 \%)$ \\
\hline Witness friend/close friend be harmed & $6(6.4 \%)$ & $2(4.3 \%)$ & $4(8.3 \%)$ \\
\hline Not understood & $4(4.3 \%)$ & $2(4.3 \%)$ & $2(4.2 \%)$ \\
\hline Loss of property/belonging & $3(3.2 \%)$ & $1(2.2 \%)$ & $2(4.2 \%)$ \\
\hline Wrongdoing & $2(2.1 \%)$ & $2(4.3 \%)$ & $0(0 \%)$ \\
\hline Dispute with another person & $2(2.1 \%)$ & $0(0 \%)$ & $2(4.2 \%)$ \\
\hline Witness other people being harmed & $1(1.0 \%)$ & $0(0 \%)$ & $1(2.1 \%)$ \\
\hline Parents argue & $1(1.0 \%)$ & $0(0 \%)$ & $1(2.1 \%)$ \\
\hline Personal conflict with another person & $1(1.0 \%)$ & $0(0 \%)$ & $1(2.1 \%)$ \\
\hline Disappointment to other & $1(1.0 \%)$ & $0(0 \%)$ & $1(2.1 \%)$ \\
\hline Physical pain & $1(1.0 \%)$ & $1(2.2 \%)$ & $0(0 \%)$ \\
\hline Disturbance & $84(19.8 \%)$ & $40(23.4 \%)$ & $44(17.3 \%)$ \\
\hline Annoying behavior of others & $36(42.9 \%)$ & $18(45.0 \%)$ & $18(40.9 \%)$ \\
\hline Unfair treatment & $12(14.3 \%)$ & $6(15.0 \%)$ & $6(13.6 \%)$ \\
\hline Mockery & $8(9.5 \%)$ & $4(9.1 \%)$ & $4(9.1 \%)$ \\
\hline Disturbance & $7(8.3 \%)$ & $4(9.1 \%)$ & $3(6.8 \%)$ \\
\hline Limitation of freedom & $6(7.1 \%)$ & $3(7.5 \%)$ & $3(6.8 \%)$ \\
\hline $\begin{array}{l}\text { Belongings were taken/broken by another } \\
\text { person }\end{array}$ & $4(4.8 \%)$ & $1(2.5 \%)$ & $3(6.8 \%)$ \\
\hline Disrespect towards privacy & $4(4.8 \%)$ & $2(5.0 \%)$ & $2(4.5 \%)$ \\
\hline Increased burden by others & $3(3.6 \%)$ & $2(5.0 \%)$ & $1(2.3 \%)$ \\
\hline Forced & $2(2.4 \%)$ & $1(2.5 \%)$ & $1(2.3 \%)$ \\
\hline Back biting & $2(2.4 \%)$ & $0(0 \%)$ & $2(4.5 \%)$ \\
\hline Others & $6(1.4 \%)$ & $1(0.6 \%)$ & $5(2.0 \%)$ \\
\hline Disorder & $3(50.0 \%)$ & $0(0 \%)$ & $3(60.0 \%)$ \\
\hline Bad mood & $2(33.3 \%)$ & $0(0 \%)$ & $2(40.0 \%)$ \\
\hline Harm others & $1(16.7 \%)$ & $1(100 \%)$ & $0(0 \%)$ \\
\hline Irrelevant answers & $7(1.6 \%)$ & $1(0.6 \%)$ & $6(2.4 \%)$ \\
\hline Blank & $37(8.7 \%)$ & $17(9.9 \%)$ & $20(7.9 \%)$ \\
\hline TOTAL & $425(100 \%)$ & $171(100 \%)$ & $254(100 \%)$ \\
\hline
\end{tabular}




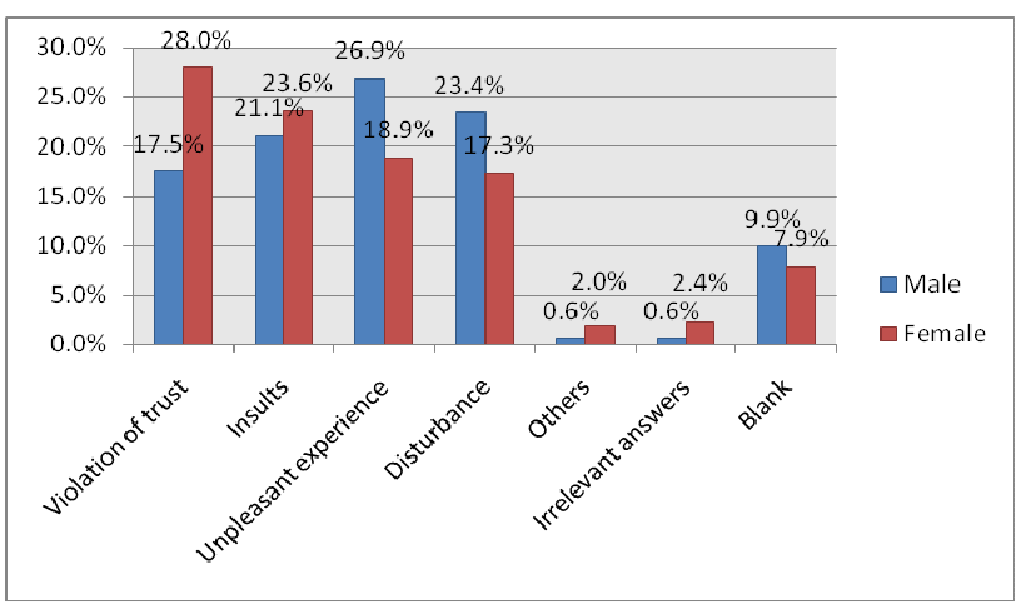

Figure 2. Sex differences in causes of anger among senior high school students

\section{Chi-Square Tests}

\begin{tabular}{|c|c|c|c|}
\hline & Value & $d f$ & $\begin{array}{l}\text { Asymp. Sig. } \\
\text { (2-sided) }\end{array}$ \\
\hline Pearson Chi-Square & $13.670^{\mathrm{a}}$ & 6 & .034 \\
\hline Likelihood Ratio & 14.234 & 6 & .027 \\
\hline $\begin{array}{l}\text { Linear-by-Linear } \\
\text { Association }\end{array}$ & .014 & 1 & .907 \\
\hline $\mathrm{N}$ of Valid Cases & 425 & & \\
\hline
\end{tabular}

a. 4 cells $(28.6 \%)$ have expected count less than 5 . The minimum expected count is 2.41 .

Figure 3. Chi square test

\section{Discussion}

Using an indigenous psychology analysis the current study aims to explain the causes of anger among Indonesian students. The results of the study demonstrate that Indonesian students become angry because of four main reasons, namely because of insults, disturbance, violation of trust, and encounter an unpleasant experience. In addition to the causes of anger that were revealed in this study, differences among male and female students were also found. While male students were more likely to become angry due to unpleasant experience, female students were more likely to report anger when they experience violation of trust.

The findings in this study are unique, considering that they support some previous findings on the causes of anger; however offer some new perspectives that may also refine our understanding of anger from a contextual perspective. As indicated by the study, insult, disturbance, and violation of trust were the primary causes of anger. These causes are strongly associated with another subject who was deemed responsible for the anger and therefore supports the notion that these causes are important elements in eliciting anger. Such findings support the theoretical assumptions of other accountability (Kuppens et al., 2003). Even for the category unpleasant experience, a considerable number of events relate with unpleasant experiences with other people for example conflict with parents, friends seeing their friends being hurt, problems in intimate relationships and etc. Only a few unpleasant experiences were reported not to be related with others, namely experiencing physical pain, loss of property, committed a wrongdoing.

Explaining the findings cannot be separated from the context of which the data was collected. Indonesia is distinct with its collectivistic culture. Collectivistic culture foster interdependent selves and in-group goals, 
encourage relatedness and communal relationships (Matsumoto, 2010). Under such circumstances it becomes no surprise that the most dominant causes for anger relates with interpersonal relationships with other people and how responses reflect receiving negative consequences from another person. More specifically in Javanese culture, the social philosophy of harmony 'rukun' extends great importance. This philosophy emphasizes social relationships are characterized by being quiet and peaceful, friendship, without quarrel and strife, and a united purpose while helping each other (Mulder, 2005). It's is clear that actions of violating trust, insults, and annoying behavior damages the equilibrium of harmonious relationships and therefore may serve as justifications to elicit anger.

In contrast to previous studies of anger, the current study fails to support the claim that goal obstruction serves as an important factor in eliciting anger. This becomes alarming considering that is has been argued as an important factor to elicit anger by theorists investigating anger (Kuppens et al, 2003; Wranik and Scherer, 2010). Once again such differences may susceptibly be explained by the variations of emotional dynamics between individualistic and collectivistic cultures.

Markus and Kitayama (1991) provide a useful account discerning differences of emotionality between individualistic and collectivistic cultures under the notion of the "two construals of self". The independent construal of self defines the individual as independent which requires constructing oneself as an individual whose behavior is organized and made meaningful primarily by reference to one's own repertoire of thoughts, feelings and action, rather than by referencing to the thoughts, feelings and actions of others. In contrast, the interdependent self construal is simply the opposite of the independent construal and is more common in collectivistic cultures. In terms of the emotional dynamics between these two entities, independent selves are more ego-focused as opposed to others-focused in that the individual's internal attributions (needs, desires, goals, abilities) serve as the primary reference for emotion elicitation such as anger, frustration or pride. In contrast the primary reference for others-focused emotions include sympathy, feelings of interpersonal communion, shame which result from being sensitive to others, taking the perspective of the other and attempting to promote interdependence.

Specifically in the Javanese context, Mulder (2005) explains that Javanese restricts individual expression of the individual self. Personal expression, especially showing off emotions, is impolite, embarrassing, and a violation of the privacy of others. Furthermore the expression of sepi ing pamrih, rame ing gawe (passive self-interest but active work) is important in Javanese ethics (Mulder, 2005). Passive self-interest refers to being unselfish and not to be driven by desires of personal gain. On the other hand 'active in work' refers to being active in performing good deeds for the benefit of all. Taking these explanations into consideration, it is clear that goal obstruction is highly characteristic of individualistic cultures. It explains why goal obstruction was perceived as central to the elicitation of anger in previous studies, since they were performed in western individualistic settings and therefore explains why the relevance of goals was not evident in the current study.

Finally Berkowitz and Harmon-Jones (2004) offer another approach to understanding the causes of anger and why appraisals are able to elicit anger. According to them, such appraisals of frustration, goal incongruence, obstacles to goal attainment, and negative outcomes generally all refer to an aversive condition, or a state of affairs that the person ordinarily seeks to escape or avoid, and it is this the experienced displeasure produced by the aversive situation that presumably gives rise to the anger. This line of thought serves as an alternative explanation in understanding the findings of the current study. Being insulted, disturbed, violation of trust, and encountering unpleasant experiences all refer to aversive conditions of which the subjects would avoid and considering it produces a strong negative affect therefore the subject would react in anger when encountering such circumstances.

Based on the cross-tabulation of causes of anger and sex, male and female students differ to what makes them most angry. Male students become most angry when they encounter unpleasant experience (26.9\%) while female students are most angry when violation of trust has occurred (28\%). The largest difference between male 
Causes of anger among senior high school students in Indonesia: An indigenous psychology approach

and female students is for the category violation of trust (Female: 28\%; Male 17.5\%) indicating that women are more sensitive to issues of trust compared to men. This finding can be explained by the fact that women are more attuned to their social networks (Fischer \& Evers, 2010). Considering that they place large weight on their interactions with others, including trust, therefore its violation can serve as a much more severe aversive state which can lead to anger.

\section{Implication and Recommendation}

Understanding the causes of anger has implications in the educational context. Unpleasant feelings have been shown to negatively impact learning and problem solving and therefore the classroom context should be managed in a way that minimizes the experience of unpleasant emotions (Eynde, Corte, \& Verschaffel, 2007). In light of the findings in the current study, considering that anger is largely provoked by interpersonal relations, therefore it becomes the task of the teacher or the school authorities to anticipate situations related with student-student relationships or teacher-student relationships. In a classroom which consists of students of different ethnic groups and religion, it would be essential to build trust among students to allow them to view other students as partners in collaborative learning as opposed to out-group rivals. This allows students to direct their focus on the learning process compared to sentiment of other people.

The current study offers evidence upon how different cultural contexts differentiate between appraisals of anger causes. Future studies should investigate whether these patterns are identical among different age groups for example adults. The current findings serve as a preliminary investigation towards causes of anger in Indonesia and since the investigation took place in the Javanese Yogyakarta, it cannot be generalized to other Indonesian islands or Indonesian cultures. Considering Indonesia owns a highly diverse culture, consisting of Sundanese, Madurese, Batak, Bugis, and many more, further studies also be encouraged to explore the realms of anger among these different cultures. Furthermore the subjects in the study are imbalanced with larger female subjects. Future studies should try to balance the composition between male and female subjects to obtain a more representative description of the phenomenon.

\section{References:}

Arnett, J. J. (1999). Adolescent storm and stress, reconsidered. American Psychologist, 54(5), 317-326. http://dx.doi.org/10.1037/0003-066X.54.5.317

Averill, J. R. (1983). Studies on anger and aggression: Implications for theories of emotion. American Psychologist, 1145-1160. http://dx.doi.org/10.1037/0003-066X.38.11.1145

Berkowitz, L., \& Harmond-Jones, E. (2004). Toward an understanding of the determinants of anger. Emotion, 4(2), 107-130. http://dx.doi.org/10.1037/1528-3542.4.2.107

Carpenter, S., \& Halberstadt, A. G. (1996). What makes people angry? Laypersons' and psychologists categorizations of anger in the family. Cognition and Emotion, 10(6) 627-656. http://dx.doi.org/10.1080/026999396380088

Ellsworth, P. C., \& Smith, C. A. (1988). From appraisal to emotion: Differences among unpleasant feelings. Motivation and Emotion, 12(3), 271-302. http://dx.doi.org/10.1007/BF00993115

Eynde, P. O., De Corte, E., \& Lieven. (2007). Students' emotions: A key component of self-regulated learning? In P. A. Schutz \& R. Pekrun (Eds.), Emotion in education. Amsterdam: Elsevier.

Fischer, A. H., \& Evers, C. (2010). Anger in the context of gender. In M. Potegal, G. Stemmler, \& C. Spielberger (Eds.), International handbook of anger: Constituent and concomitant biological, psychological, and social processes (pp. 349-360). New York: Springer Science-Business Media, LLC.

Kim U., Yang K., \& Hwang K. (Eds.) (2006). Indigenous and cultural psychology: Understanding people in context. New York: Springer Science-Business Media, LLC.

Kuppens, P., Mechlehen, I. V., Smits, D. J. M., \& DeBoeck, P. (2003). The appraisal basis of anger: specificity, necessity, and sufficiency of components. Emotion, 3(3), 254-269. http://dx.doi.org/10.1037/1528-3542.3.3.254 
Thontowi, H. B., Wulandari, R. C., Hakim, M. A., Moordiningsih, Yuniarti, K. W., \& Kim, U.

Markus, H. R., \& Kitayama, S. (1991). Culture and the self: Implications for cognition, emotion, and motivation. Psychological Review, 98(2), 224-253. http://dx.doi.org/10.1037/0033-295X.98.2.224

Matsumoto, D., Yoo, S. H., \& Chung, J. (2010). The expression of anger across cultures. In M. Potegal, G. Stemmler, \& C. Spielberger. (Eds.), International handbook of anger: Constituent and concomitant biological, psychological, and social processes (pp. 125-138). New York: Springer Science-Business Media, LLC.

Mesquita, B. (2003). Emotions as dynamic cultural phenomena. In R. J. Davidson, K. R. Scherer, \& H. H. Goldsmith (Eds.), Handbook of affective sciences (pp. 871-890). New York: Oxford University Press.

Mulder, N. (2005). Mysticism in Java: Ideology in Indonesia (2 ${ }^{\text {nd }}$ ed.). Yogyakarta: Kanisius.

Roseman, I. J., Dhawan, N., Rettek, S. I., Naidu, R. K., \& Thapa, K. (1995). Cultural differences and cross-cultural similarities in appraisals and emotional responses. Journal of Cross-Cultural Psychology, 26(1), 23-48. http://dx.doi.org/10.1177/0022022195261003

Schieman, S. (1999). Age and anger. Journal of Health and Social Behavior, 3, 273-289. http://dx.doi.org/10.2307/2676352

Smith, C. A., \& Ellsworth, P. C. (1985). Patterns of cognitive appraisal in emotion. Journal of Personality and Social Psychology, 48(4), 813-838. http://dx.doi.org/10.1037/0022-3514.48.4.813

Strauss, A. L. (2003). Qualitative analysis for social scientists. Cambridge: Cambridge University Press.

Weber, H. (2004). Explorations in the social construction of anger. Motivation and Emotion, 28(2), 197-219. http://dx.doi.org/10.1023/B:MOEM.0000032314.29291.d4

Wranik, T., \& Scherer, K. R. (2010). Why do I get angry? A componential appraisal approach. In M. Potegal, G. Stemmler, \& C. Spielberger. (Eds.), International handbook of anger: Constituent and concomitant biological, psychological, and social processes (pp. 243-266). New York: Springer Science-Business Media, LLC. 